\title{
Adenylate Kinase: A Ubiquitous Enzyme Correlated with Medical Conditions
}

\author{
Mihaela lleana lonescu ${ }^{1,2}$ (D)
}

Published online: 21 January 2019

(c) Springer Science+Business Media, LLC, part of Springer Nature 2019

\begin{abstract}
Adenylate kinase is a small, usually monomeric, enzyme found in every living thing due to its crucial role in energetic metabolism. This paper outlines the most relevant data about adenylate kinases isoforms, and the connection between dysregulation or mutation of human adenylate kinase and medical conditions. The following datadases were consulted: National Centre for Biotechnology Information, Protein Data Bank, and Mouse Genomic Informatics. The SmartBLAST tool, EMBOSS Needle Program, and Clustal Omega Program were used to analyze the best protein match, and to perform pairwise sequence alignment and multiple sequence alignment. Human adenylate kinase genes are located on different chromosomes, six of them being on the chromosomes 1 and 9. The adenylate kinases' intracellular localization and organ distribution explain their dysregulation in many diseases. The cytosolic isoenzyme 1 and the mitochondrial isoenzyme 2 are the main adenylate kinases that are integrated in the vast network of inflammatory modulators. The cytosolic isoenzyme 5 is correlated with limbic encephalitis and Leu673Pro mutation of the isoenzyme 7 leads to primary male infertility due to impairment of the ciliary function. The impairment of the mitochondrial isoenzymes 2 and 4 is demonstrated in neuroblastoma or glioma. The adenylate kinases are disease modifier that can assess the risk of diseases where oxidative stress plays a crucial role in pathogenesis like metabolic syndrome or neurodegenerative diseases. Because adenylate kinases has ATP as substrate, they are integrated in the global network of energetic process of any organism therefore are valid target for new pharmaceutical compounds.
\end{abstract}

Keywords Adenylate kinase $\cdot$ Nucleotide metabolism $\cdot$ Phosphotransfer enzymes · AMP-activated protein kinase $\cdot$ Adenine nucleotide $\cdot$ Homeostasis

\begin{tabular}{lll}
$\begin{array}{ll}\text { Abbreviations } \\
\text { ADP }\end{array}$ & dNTP \\
AK & Adenosine diphosphate & DGYP \\
AMP & Adenylate kinase & GTP \\
AMPK & Adenosine monophosphate & hCINAP \\
Ap5A & AMP-activated protein kinases & \\
& P1,P5-di(adenosine-5') & MGI \\
ATP & pentaphosphate & MMAF \\
B4P & Adenosine triphosphate & \\
BLAST & Bis(adenosine)-5'-tetraphosphate & NCBI \\
BLOSUM & Basic local alignment search tool & \\
CDP & BLOcks SUbstitution Matrix & NTP \\
& Cytidine diphosphate & P-loop \\
\hline $\begin{array}{l}\text { Mihaela Ileana Ionescu } \\
\text { mionescu@umfcluj.ro }\end{array}$ & PCD \\
1 & PDB \\
Department of Microbiology, Faculty of Medicine, Iuliu & PRKACB \\
Haţieganu University of Medicine and Pharmacy, 6 Louis & RNAi \\
Pasteur, Cluj-Napoca 400349, Romania & RNP \\
County Emergency Clinical Hospital, Cluj-Napoca, Romania &
\end{tabular}

Deoxy-nucleoside triphosphates Aspartic acid glycine tyrosine proline Guanosine triphosphate Human coilin interacting nuclear ATPase protein Mouse genomic informatics Multiple morphological abnormalities of the sperm flagella National Centre for Biotechnology Information Nucleoside triphosphates Phosphate-binding loop Primary ciliary dyskinesia PROTEIN data bank Protein kinase c-AMP activated catalytic subunit beta RNA-mediated interference Ribonucleoprotein 
SGK Serine glycine lysine

UMP-CMP kinase Uridine monophosphate-cytidine monophosphate kinase

\section{Introduction}

Adenylate kinase (AK)—ATP: AMP phosphotransferase; EC 2.7.3.4-is a small enzyme that belong to the nucleoside monophosphate (NMPs) kinase family which are key enzyme of nucleotide metabolism [1, 2]. It is described in archaea, bacteria, and as well eukarya and catalyses a critical reaction in cell life ATP + AMP $\leftrightarrow 2$ ADP. Although ATP is the substrate for most AKs [3], the isoenzyme 3 uses GTP instead (GTP: AMP phosphotransferase; EC 2.7.4.10).

The structural and biochemical properties has been thoroughly studied for a long time [4] and a lot of AKs mutants has brought new details insight the conformational transition during catalysis [5, 6]. Why this tiny enzyme may claim for attention of so many research groups? At first glance, one might say there are no many new things to say about this subject, but recent outstanding studies reveal unexpected substantial elements which position AKs at the top of the list of markers that could help early diagnosis of the most diverse diseases or design AKs as valuable targets for innovative treatments. However, we must first look at AK particular features. Trying to find out which are the most important AKs' properties raises many difficulties. For instance, biochemical studies bring into attention their kinetic properties whereas crystallographic studies focused on decipher the intimate relationships between AK segments and different ligands. Looking only at one approach may deflect our attention from the big picture. In fact, why should someone pay attention at AKs?

First, the interconversion of adenine nucleotide is a crucial step in energetic metabolism. AKs involvement in ATP regulation is linked with other intracellular process like stress, circadian rhythm, and malignant transformation in cancer [7-9]. Second, AK is subjected to large conformational changes during catalysis, therefore the interest in resolving quaternary structure of enzymes of different origins [10]. More, the conformational changes during catalyses, bring new perspective into the field of molecular mechanisms of other enzymes [11]. The substrate-free AK is in so-called open conformation. The substrates binding first trigger a minor movement of the AMP binding site, then large movement of the LID domain over the ATP resulting in a closed conformation [2, 6, 12]. Also, $\mathrm{AK}$ isoforms are separated in short-AK and long-AK, the last with 27-residues long insertion in the central part of the enzyme [13, 14]. The divergence of the long and short AK isoenzymes occurs before differentiation in subcellular localization or substrate specificity [15].
Interest in the implications of adenylate kinases on human pathology is not new, regulation of intracellular AMP levels being essential for multiple cellular processes [8, 16, 17]. Due to its ubiquities, AK may be a solution for some cancers or could be a valid target for new antibiotics. If we discuss cancer therapy, the nine human $\mathrm{AK}$ isoezymes are, for sure, viable issues. The aim of the present paper is to get fresh data into the classification and medical applications of AKs. It is not only a revision of implication of AK in human diseases, but rather a deep search of connections of AKs with other metabolic pathways. The study was organized in two main parts: the first part is an overview of human AKs and the second part is an analysis of the connection of human AKs and their mutants with pathological conditions is a meta-analysis of relevant connections of AKs with clinical conditions.

\section{Materials and Methods}

In order to find out the relevant data about structural features of human AKs, two protein databases have been usedNational Centre for Biotechnology Information (NCBI) (https://www.ncbi.nlm.nih.gov/protein) and Protein Data Bank (https://www.rcsb.org/pdb/home/home.do) (PDB). The NCBI was used for retrieving sequences and for Standard Protein BLAST or SmartBlast search. The PDB was used for crystal structure searching. The SmartBLAST tool was used to analyze the best protein match between 27 wellstudied organisms included in the landmark database. While Homo sapiens is included in the SmartBLAST search for the best matches, we believe SmartBlast meets the needs of this study. When a deeper analysis of human isoezymes was required, the pairwise sequence alignment, the EMBOSS Needle Program was used [18]. The default parameters were applied-Matrix EBLOSUM62, which is a variant of BLOSUM62, gap penalty 10.0 and extend penalty 0.5 . Multiple sequence alignment was by the Clustal Omega program (https://www.ebi.ac.uk/Tools/msa/clustalo/). The following gene databases have been consulted: NCBI (https://www. ncbi.nlm.nih.gov/gene/) and Mouse Genomic Informatics (MGI) (http://www.informatics.jax.org/). The Dassault Systèmes BIOVIA-Discovery Studio Modeling Environment, Release 2017, San Diego: Dassault Systèmes, 2016-allows the visualization of the protein structures and the analysis of protein-ligand interactions of the residues mutated or deleted in some diseases where AKs activity is reduced (http://accelrys.com).

\section{Human Adenylate Kinases}

There are nine isoezymes and several sub-forms of AKs described in eukaryotes, but only few of them are noticed in bacteria and archaea. Very often, attempts to understand 
human AKs begin with the search for a similar isoenzyme and carry out experiments that allow, by deduction, the understanding of implications in human pathology. Attempts to classify AKs have been hampered by the identification of new isoenzymes, which inevitably imposes their annotation [19]. If isoenzymes $2-9$ belong to the adenylate kinase family members in TIGR01351, human isoenzyme 1 is more closely to the subfamily of eukaryotic UMP-CMP kinases (TIGR01359) [20].The nine AKs described in eukaryotes are distributed in different intracellular compartments, where they play a central role in the maintenance of energetic homeostasis by regulation of nucleotide ratio. AKs isoezymes 1, 5, 7 and 8 are located in cytosol, the isoezymes 6 is found in nucleus, and the isoezyme 9 shows a free difusion between the cytosol and the nucleus [21]. The AKs isoezymes 2,3 , and 4 are mitochondrial isoezymes but while the AK3 and AK4 are found in the mitochondrial matrix, the AK2 is located in the intermembrane space instead. Although human AKs have many in common, especially their structures and functional properties, intracellular localization explains some of their distinct properties. Not only intracellular localization is relevant, but their expression in some body organs is correlated with specific pathologies. The most striking example is isoezyme 5 , which is expressed exclusively in the brain. In the Fig. 1, are shown the cytosolic and mitochondrial human adenylate kinases isoenzymes and the chromosomes were their corresponding genes are located. Most human AKs genes are located on the chromosomes 1 and 9. The $A K 7$ gene is the only exception cytosolic AK that is found on chromosome 14 .

\subsection{Cytosolic Adenylate Kinases}

The AK1 (accesion number: AAH01116) - 194 residues-is one of the most studied human isoenzyme. The $A K l$ gene is located on the chromosome 9 on the location 9q34.11 (NCBI Gene ID: 203) and is highly expressed in skeletal muscle, brain and erythrocytes. It has the crystal structure established in complex with bis(adenosine)-5'-tetraphosphate (B4P) and malonate ion (PDB ID: 2C95) or in complex with P1,P5-di(adenosine-5')pentaphosphate (Ap5A) (PDB ID: 1Z83). It is similar to the enzyme of many organismsshows $88 \%$ identity with Mus musculus counterparts and 60\% with Caenorhabditis elegans, respectively.

The AK5 (accesion number: AAH33896) - 537 residues-is very well conserved in Eukarya domain. It is very similar to the enzyme from different organism, showing more than $90 \%$ identity with its eukaryotes counterparts and an interesting similarity with AK1 $-58 \%$ with human AK1 and 49\% with Caenorhabditis elegans AK. The $A K 5$ gene is located on the chromosome 1 on the location 1p31.1 (NCBI Gene ID: 26289). It was crystallized in

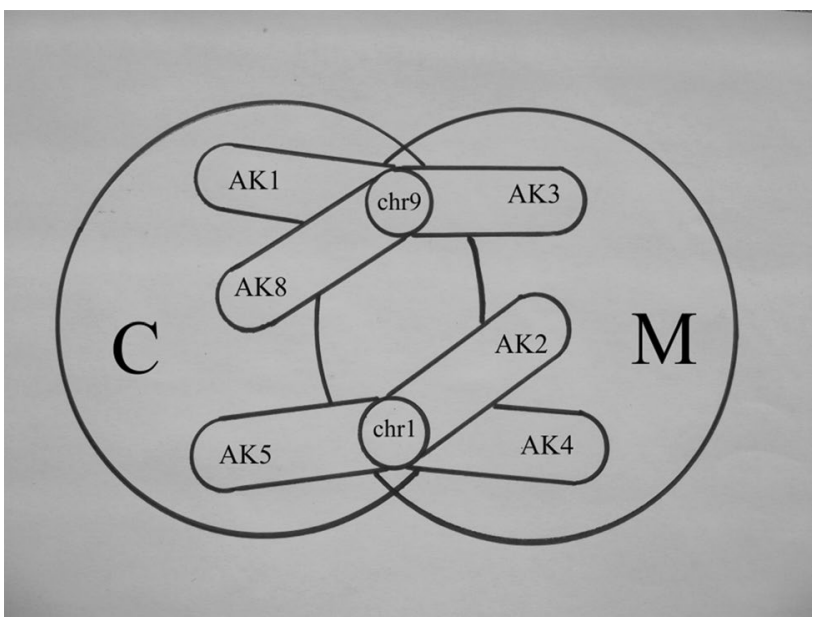

Fig. 1 Intracellular localization of cytosolic and mitochondrial AKs and chromosomal localization of the corresponding genes. $C$ means cytosol, $M$ means mitochondria, $c h r$ means chromosome. The $A K 7$ gene is the only exception cytosolic AK that is found on chromosome 14

two conformations - in closed conformation with adenosine monophosphate and in open conformation without substrate (PDB ID: 2BWJ).

The AK7 (Accesion number: NP_689540)—723 residues, and the AK8 (Accesion number: NP_689785)—479 residues, are also well conserved in eukaryotes. The human isoenzyme 7 shows particular structural and functional properties among AK family [22]. It is particularly expressed in bronchus and testis [23]. AK7 contains three conserved domains. Near the N-terminus part of the protein between the 147 and 310 residues there is $\mathrm{WcaG}$ domain which belong to nucleoside-diphosphate-sugar epimerase superfamily, between the 367 and 548 residues there is the adenylate kinase domain, and between the 678 and 720 residues, near the $\mathrm{C}$-terminus part of the protein there is located Dpy30 motif which may be a dimerisation motif. The isoenzyme 8 shows conserved residues when compared with AK from anaerobic or anaerobic aerotolerant bacteria $-31 \%$ sequence identity with AK from Streptococcus pneumoniae, 28\% with Shewanella oneidensis, and 29\% with Clostridioides difficile, respectively. The most relevant conserved residues belong to the Walker A motif (P-loop)—phosphate-binding loop. The gene encodes $A K 7$ is located on the chromosome 14 on the location 14q32.2 (NCBI Gene ID: 122481) and the $A K 8$ gene is on the chromosome 9 on the location $9 \mathrm{q} 34.13$ (NCBI Gene ID: 158067).

The AK9 subcellular localisation of AK9 (NCBI Gene ID: 221264) is not clearly established, recent studies suggest a free difusion between the cytosol and the nucleus [21]. Probably there are more AKs isoenzymes to be discovered or AK9 has unique characteristics that are not fully understood. 
The details about AK9 are done along with the AK6, another isoenzyme found in the nucleus.

\subsection{Mitochondrial Adenylate Kinases}

The $A K 2$ gene is located on the chromosome 1 on the location 1p35.1 (NCBI Gene ID: 204) and is highly expressed in the mitochondrial intermembrane space of heart, liver, spleen and kidney [24, 25]. The AK2 isoenzyme (Accesion number: AAC52061) - 239 residues - has been co-crystallized with bis(adenosine)-5'-tetraphosphate (B4P) (PDB ID: 2C9Y). Although it is very conserved in Eukarya domain, it shows a remarkable identity with other isoenzymes-45\% identity with human AK3, 39\% with Drosophila melanogaster, $40 \%$ with human AK4, 52\% with Glycine max AK4, 41\% with Mus musculus AK4, 55\% with Arabidopsis thaliana AK1 - or with its prokaryotes counterparts- $54 \%$ with AK from Escherichia coli str. K-12 substr. MG 1655 and 50\% with AK from Pseudomonas aeruginosa PAO1. Probably the similarity of human AK2 with Gram-negative prokaryotes' AKs, could be related with the mitochondrial origin from $\alpha$-Proteobacteria symbiont [26]. However, the multiple sequence alignment of human AK2 with other bacterial adenylate kinases presented in the Fig. 2, do not reveals striking differences on the residues belonging to the catalytic sites.

The AK3 is a GTP:AMP phosphotransferase (accesion number: AAH13771) with 227 residues and is found in mitochondrial matrix. It was crystallized without co-factor as a monomeric protein (PDB ID: 1ZD8). The $A K 3$ gene is located on the chromosome 9 on the location 9p24.1 (NCBI Gene ID: 50808), and is expressed ubiquitously in all tissues.

The $A K 4$ gene is located on the chromosome 1 on the location 1p31.3 (NCBI Gene ID: 205). The AK4 (accesion number: P27144), named also AK3-like due to its homology with AK3-99\% identity, is a GTP:AMP phosphotransferase with 223 residues and is found in mitochondrial matrix. As its structure was intensively studied, there are three crystal structure deposited in Protein Data Bank-two of them permit to observe the well-known motion of AK4. While 2AR7 was crystallized in open conformation, 2BBW was co-crystallized with diguanosine pentaphosphate in closed conformation, demonstrating that this isoenzyme follow the typical motion during catalysis. More, the point-mutation

$$
\begin{aligned}
& \text { Human AK2 } \\
& \text { T.maritima } \\
& \text { E. coli } \\
& \text { P.aeruginosa } \\
& \text { C.difficile } \\
& \text { S.aureus }
\end{aligned}
$$

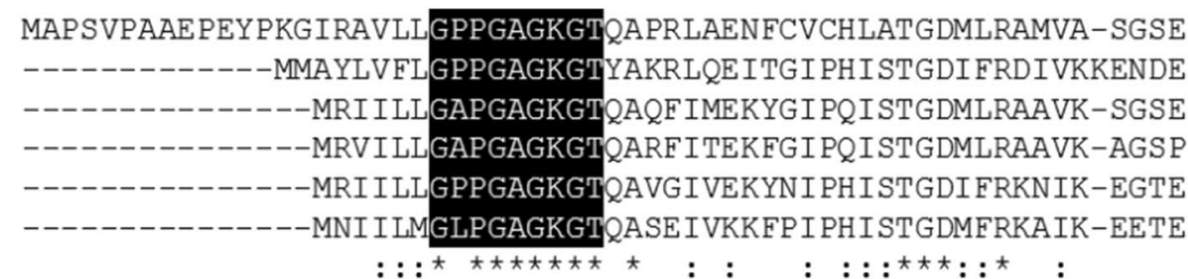

LGKKLKATMDAGK LVSDEMVVELIEKNLETPLCKNGFLLDGFPRTVRQAEMLDDLMEKRK LGKKIKE IMERGE LVPDELVNEVVKRRLSEKDCERGF I LDGYPRTVAQAE FLDGFLKTQN LGKQAKD IMDAGK LVTDELVIALVKERIAQEDCRNGFLLDGFPRTI PQADA----MKEAG LGQQVKGVMDSGG LVSDDI IIALIKERITEADCAKGFLFDGFPRTI PQAEA----LKDAG LGKKAKEYMDQGL LVPDELTVGLVTDRISQEDCKNGFMLDGFPRNVAQGEHLDIFLKNAG LGKEAKSYMDRGE LVPDEVTVGIVKER ISEDDAKKGFLLDGFPRTIEQAEALNNIMSELD

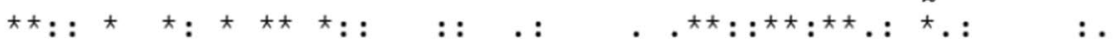

EKLDSVIEFSIPDSLLIRRITGRLIHPKSGRSYHEEFNPPKEPMKDDITGEPLIRRSDDN KELTAAVLFEVPEEVVVQRLTARRICPKCGR IYNLISLPPKEDELCDDCKVKLVQREDDK INVDYVLEFDVPDELIVDRIVGRRVHAPSGRVYHVKFNPPKVEGKDDVTGEELTTRKDDQ VTIDHVVEIAVDDEEIVSRIAGRRVHPASGRVYHTEHNPPKVAGKDDVTGEELIQREDDK ISLDKVVNIEVDKSILVSRAVGRRICKSCGATYHVEFNPPKVEGVCDVCQGELYQRADDN RNIDAVINIEVPEEELMNRLTGRRICESCGTTYHLVFNPPKVEGICDIDGGKLYQREDDN
Fig. 2 Multiple sequence alignment of the human AK2 and AKs from Thermotoga maritima, Escherichia coli, Pseudomonas aeruginosa, Clostridioides difficile, and Staphylococcus aureus. On black background was selected the Walker A motif GXXXXGKGT/S which is the phosphate-binding loop, in italic were selected the lysine and valine very well conserved residues, and on grey background were selected the aspartic acid and arginine residues, well conserved in the adenylate kinase family, residues which belong to the consensus sequence [LIVMFYWCA] - [LIVMFYW] (2) - D - G - [FYI] - P - R - Z (3) $-[\mathrm{NQ}], *$ (asterisk) indicates positions which have a single, fully conserved amino acid residue; : (colon) indicates conservation indicates positions which have a single, fully conserved amino acid residue; : (colon) indicates conservation between groups of strongly similar properties 
of a well-conserved residue-Leu171Pro-located in one hinge that connect the CORE and LID domains, demonstrates a different closed conformation, so-called twistedand-closed conformation, without substrate triggering (PDB ID: 3NDP) [27]. Apart of similarity with human mitochondrial AK3 and AK2, shows 40-42\% identity with AK1 from Arabodopsis thaliana, AK2 from Saccharomyces cerevisiae, or its counterparts from Pseudomonas aeruginosa, Escherichia coli, Plasmodium falciparum, Caenorabditis elegans.

\subsection{Adenylate Kinases Found in Nucleus}

The AK6 gene is located on the chromosome 5 on the location 5q13.2 (NCBI Gene ID: 102157402). The AK6 (accesion number: AAO16520)—536 residues-is almost identical with AK5 (99\%). Human adrenal gland protein AD-004 (PDB ID: 1RKB)-173 residues-was identify as AK6 isoform with unique properties important for cellular functional activities. By its nuclear localization, AK6 has a central role in phosphotransfer network, all types of NTP (nucleoside triphosphates) and dNTP (deoxy-nucleoside triphosphates) could be phosphate donors to produce ADP (adenosine diphosphate) and CDP (cytidine diphosphate), but CTP shows fivefold higher activity than that of ATP. It is so versatile thus it could regulate simultaneously the ATP/ ADP and GTP/GDP ratios [28]. We can assume that this isoenyme' functions is much more complex as recent data demonstrated that human coilin interacting nuclear ATPase protein (hCINAP), previously designated as AK6 exhibit an extended catalytic activity which control the Cajal bodies assembly and disassembly in the nucleus of human cells [29].

AK9 is a nucleoside mono- and diphosphate kinase due to its broad phosphatase activity, the local concentration of substrates probably influences catalytic activity [21, 30]. The $A K 9$ gene is located on the chromosome 6 on the location 6q21 (NCBI Gene ID: 221264). There are two human isoforms of AK9. The isoforme 1 (accesion number: NP_001138600) with 1911 residues is very similar with AK9 of different origin. By SmartBLAST search a $30 \%$ identity with AK5 chloroplast-like protein from Glycine max was noticed. The isoform 2 (accesion number: NP_659462) with 421 residues shows some interesting similarities-29\% identity with AK1 from Plasmodium falciparium and 26\% identity with AK from Pseudomonas aeruginosa PAO1, $24 \%$ identity with UMP-CMP kinase-like from Glycine max. For both AK9 isoforms, the most important conserved residues are SGK from Walker A motif and DGYP residues from consensus sequence.

In looking for AKs similarities, I have noticed that human isoezymes are very similar to AKs orthologs identified in other eukaryotes. There remains an open discussion about the correlation between the specific subcellular localization of the AKs isoenzymes and their involvement in other regulatory pathways in addition to nucleotide metabolism.

\section{Implication of Adenylate Kinases in Human Diseases}

Current approaches attempt to measure specific markers for many diseases that are silent in treatable stages. It is not unusual to find out that deregulation of particular enzymes add new insight in early diagnosis of cancers or other diseases. Because adenylate kinase has ATP as substrate-the universal energy molecule-more definitely is integrated in the global network of energetic process of any organs of human body. More, there are three AKs izoenzymes located in mitochondria, a dynamic organelle whose dysfunction is directly linked with metabolic diseases, cancer, neurodegeneration, and aging [31].

\subsection{Clinical Implication of Adenylate Kinases}

\subsubsection{Human Adenylate Kinases and Immunity and Inflammation}

Adenylate kinase phenotypes are not random but associated with human adaptability on environmental conditions. A retrospective study demonstrates a connection between the AK1 phenotypes and the season of conception and foetal sex. The explanation could reside on metabolic adaptability and immune modulation to environmental changes during conception [32]. It is not a new concept of adapting life to seasonal changes but the exact role of AK is not established-the enzyme plays a role in shaping human life or its phenotypic variation is a consequence of the adaptation process.

The immune modulation in helmints infections-very often long-standing infections-is characterized by releasing of mediators and other products of parasitic origin, which redirect the host immune system [33, 34]. A recent study shows that recombinant AK1 from Shistosoma japonicum elicit partial immune protection and the induction of Th1-response, by IL-2 and IFN- $\gamma$ (Fig. 3a). More, AK1 is expressed most in the worm stages related to egg development [35]. So, AK could be a valid option to control the zoonosis due to the nematode Shistosoma japonicum, otherwise widespread in China, the Philippines, Indonesia and Japan [36].

One of the most recent study, demonstrate that AK1 from the human vitreous fluid is responsible for maintaining an inflammatory status in diabetic eyes (Fig. 3a) [37]. Also, the ATP, ADP, and AMP ratio is crucial in ocular diseases like age-related macular degeneration, glaucoma or retinal degeneration [38-40]. 
Fig. 3 Comparative AK1 and AK2 disregulations a in inflammation and in neurodegenerative diseases; $\mathbf{b}$ in skeletal muscle (a)

\section{Inflammation/immunomodulation Neurodegenerative diseases}

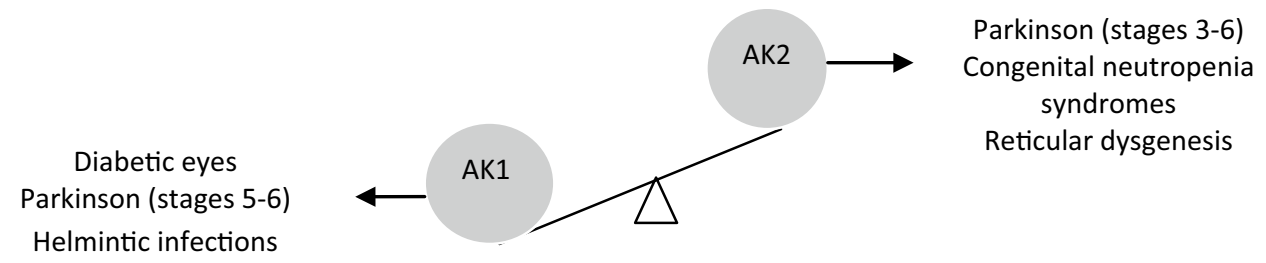

(b) skeletal muscle

Duchenne muscular dystrophy

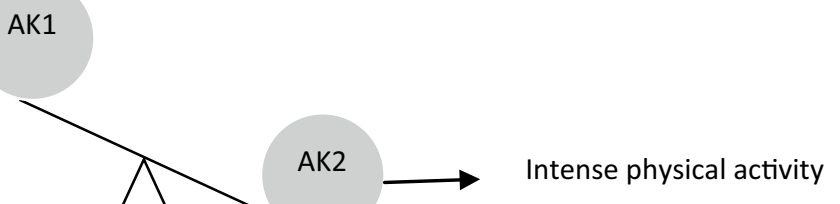

The AK2 is essential for mitochondrial respiration and, due its location on the intermembrane space of mitochondrial, plays an important role in controlling the energy metabolism of cells that requires high levels of energy, like hematopoietic stem cells or adipocyte differentiation [41, 42]. Therefore, AK2 impairment is reflected in early onset clinical conditions characterized by severe combined immunodeficiency. The absence of AK2 expression, as a result in $A K 2$ gene mutation, causes congenital neutropenia syndromes or reticular dysgenesis characterized by severe neutropenia, lymphopenia and bilateral sensorineural deafness [43-45] (Fig. 3a). Since mitochondria function contributes greatly to the control of inflammation [46], the AKs present in mitochondrial compartments are certainly integrated into the network of inflammatory modulators [47]. Dzeja and colab. design an elegant illustration of AK-catalyzed energy transfer shuttle from generation to utilization sites without apparent changes in metabolite concentration [8]. Thus, due to the intimate connection of cytosolic and mitochondrial AKs, a deeper understanding of the functions of AK isoforms can be a new approach to elucidating the inflammatory process of various diseases.

Limbic encephalitis is part of autoimmune neurological disorder, basically characterized by inflammation of limbic system. Recent studies demonstrate the presence of AK5 autoantibodies in cerebrospinal fluid and sera of patients with limbic encephalitis [48, 49]. The first study of neuropathology limbic encephalitis, clearly confirmed the correlation of inflammatory process with antibodies against intracellular antigens, histopathological examination confirmed T-lymphocytic infiltrates, mostly CD8 subtype [50].
The involvement of nucleus-localized AKs in human diseases has not been studied as much as mitochondrial and cytosolic AKs. It was recently demonstrated the connection of the AK6 with the grow of Caenorabditis elegans [51] or Arabidopsis thaliana [52]. Definitely, the parasites life cycle is influence not only by inflammatory modulators of the host, but the complex relationship parasite-host is reflected in energetic metabolism of the parasite. A BLAST search show that human AK6 is very much alike with cytosol AK5 (99\% identity) which complicated more the precise involvement of the nuclear AK6.

\subsubsection{Adenylate Kinases and Motility}

The implication of AK in ciliary function has been demonstrated long time ago [53]. ATP availability, by its subcellular compartmentation, has a direct role in cell arrangement control, most probably by controlling local actomyosin. Though, at least one missense mutation (Leu673Pro) near the Dpy-30 dimerisation motif of the isoform AK7, expressed in ciliated cells, is demonstrated to induce asthenozoospermia due to multiple morphological abnormalities of the sperm flagella (MMAF) but not primary ciliary dyskinesia (PCD) [54]. PCD is a congenital cause of respiratory disorders characterized by impairment of the ciliary function $[55,56]$. The heterogeneity of genetic abnormalities and of clinical phenotypes, hampers the development of unique diagnosis algorithm [57]. Regarding attempts to decipher PCD genetics, experimental studies have suggest that genetically uncharacterized cases of PCD may be due to mutations of AK7 [58]. 


\subsubsection{Adenylate Kinases and Metabolic Syndrome and Neurodegenerative Diseases}

In the tissues with high energy demand, AK activity greatly influences the energy supply. In skeletal muscle, the activity of some AKs isoforms is up or down regulated as a response to normal muscular exercise, hypoxia or muscular diseases. For instance, the mitochondrial AK2 is elevated in intense physical activity $[59,60]$ and AK1 expression is reduced in Duchenne muscular dystrophy [61] (Fig. 3b). Skeletal muscle activity is intrinsically linked to the use of ATP and energy homeostasis, so AK activity have an important role in metabolic syndrome [62]. More, the metabolic disorders of type 2 diabetes may be the origin of pathophysiology of neurodegenerative diseases-Parkinson's disease and Alzheimer's disease. A diminished activity of 5'-AMP activated kinase (AMPK) followed by accumulation of misfolded proteins along with decreased mitochondrial biogenesis could explain the molecular mechanisms of these diseases $[63,64]$. Further, besides of the constellation of metabolites modified in these disorders, the antioxidant defenses mechanisms are also reduced, brain is one of the most vulnerable tissue when face to oxidative damage $[65,66]$. A big picture of dysregulation of different enzymes expressed in the neurons suggests that the dynamic of some enzymes in different stage of Parkinson disease are distinctive. Speaking just about AKs, the authors demonstrated the down regulation of AK2, AK3, and AK4 in the substantia nigra at stages 3-6 and the up regulation of AK1 in the frontal cortex area 8 in the stages 5-6, the later manifestation was explained as a compensation of altered purine metabolism [67] (Fig. 3a). Therefore, AK together with other biomarkers can help assess the risk of diseases where oxidative stress plays a crucial role in pathogenesis.

\subsubsection{Adenylate Kinases and Cancer}

There are many efforts in identifying new biomarkers for early-stage cancers. The AKs, along with other regulatory protein kinases has been extensively studied. It is well known that malignant cells' growth is favored by fermentative glycosis by so-called "Warburg effect", but there are clear evidence that oxidative phosphorylation could be used, to some extent by some tumors to derived their energy [68, 69]. During cancerogensis energetic metabolism is differently regulated, total AK activity being almost three times higher in nullipotent embryonal carcinoma cells compared to normal pluripotent human embryonic stem cells [70]. More, there are evidence of production of ATP by mitochondrial oxidative phosphorylation in neuroblastoma cells, two enzymes being involved in this process-AK2 and hexokinase-2 [71]. An extensive study, by mapping $>1000$ mitochondrial proteins, identify a correlation between AK4 and glioma patient survival [1]. An explanation could be in distinct characteristics of AK4. Although AK4 share structural similarities with other isoenzymes, it shows catalytic activity only in vivo in response to various stress conditions protecting cells from $\mathrm{H}_{2} \mathrm{O}_{2}$ induced cell death [72].

\subsubsection{Gene Adenylate Kinases Mutations}

The crystal structures of some AKs isoforms allow us to thoroughly analyze the mutations described in various diseases. The deficiency of the cytosolic AK1 was long time ago associated with chronic hemolytic anemia and researchers already identify some of the molecular basis of this condition. In a patient, a transition $(\mathrm{C} \rightarrow \mathrm{T})$ in exon 6 on an allele derived from the mother results in the substitution Arg128Trp [73]. A different study showed in a patient two missmutations $118 \mathrm{G}>\mathrm{A}$ and $190 \mathrm{G}>\mathrm{A}$ result to substitutions Gly40Arg and Gly64Arg respectively, while another patient is homozygous for an inframe deletion (GAG) predicting deletion of either Asp140 or Asp141 [74]. Observing AK1 sequence and structures crystallized with different ligands (PDB ID: 2C95 and 1Z83), there are two residuesArg128 and Gly40 - that are involved in both ligands binding as it is shown in the Fig. 4. More, the residues Gly 40 and Gly64 belong to NMP-binding region and the residues Asp140 and Asp141 belong to LID-region are nearby. In the Table 1 there are shown the interactions of the AK1 residues mutated in hemolytic anemia with the ligands B4P and Ap5A.

Different mutations in $A K 2$ gene of patients with human immunodeficiency syndrome, like reticular dysgenesis, impair differentiation of granulocyte lineage and $\mathrm{T}$ and NK lymphoid lineage. The mutations or deletions associated with reticular dysgenesis have different location on AK2 sequence-start, NMP bind, LID domain or Stop region. Looking at the 3D structure of AK2 (PDB ID: 2C9Y) the residues mutated-Cys40Val, Ser213Aap, and Tyr152Thrare not involved in specific interactions with the ligand B4P (Fig. 5), but enzymatic activity is dramaticaly impaired [43].

A mutation of the polar His79 with the polar residue Gly in the nuclear hCINAP — an AK6 izoenzyme-drastically deregulates the number and the appearance of Cajal bodies in nucleus of human cells [29]. Cajal bodies role pass beyond the RNA metabolism and ribonucleoprotein (RNP) formation, protein-protein and protein-RNA interactions are essential for intracellular organization. Thus, understanding of the thermodynamic process which drive these molecular interactions would elucidate substantial aspect of protein aggregation and neurodegenerative diseases [75].

Recently a specific mutation in $A K 9$ gene associated with nucleotide deficiency in limb girdle type congenital myastenic syndrome was reported [76]. Since more than 20 genes which impaired the $\mathrm{N}$-glycosylation pathway in congenital 
$2 \mathrm{C95}$

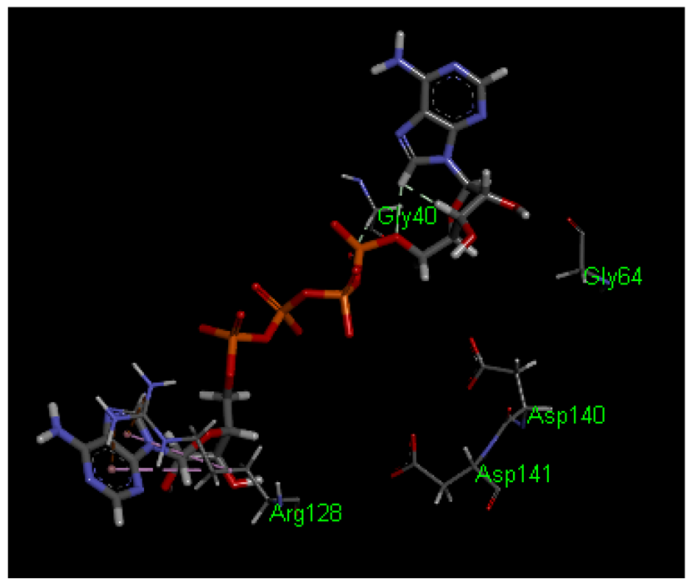

$1 \mathrm{Z83}$

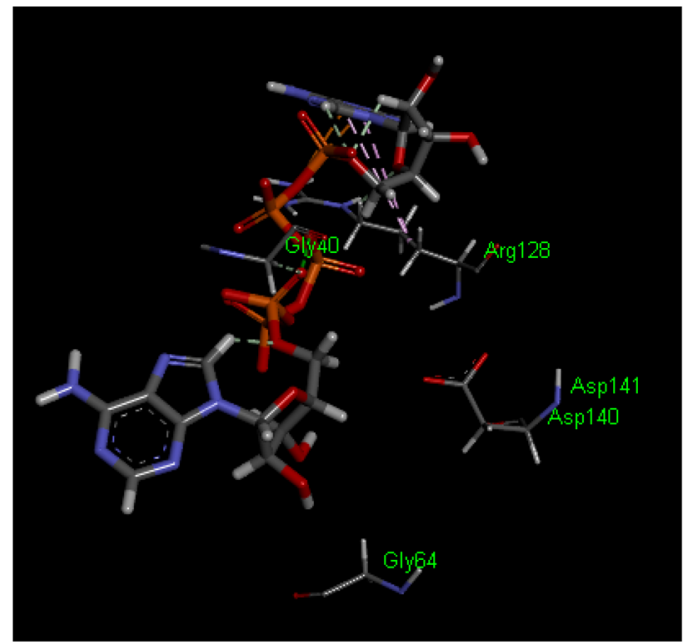

(a)

Fig. 4 a 3D interactions of the human AK1 ligands with the reference residues which are mutated or deleted in hemolytic anemia; The 2C95 ligand is $\mathrm{B} 4 \mathrm{P}$, the $1 \mathrm{Z} 83$ ligand is Ap5A; b 2D interactions; Code

Table 1 AK1 mutations involved in hemolitic anemia and the interactions of the residues substituted or deleted with the ligand co-crystallized in the 3D structures deposed in ProteinData Bank-2C95 and $1 \mathrm{Z83}$

\begin{tabular}{|c|c|c|}
\hline PDB ID & $2 \mathrm{C} 95$ & $1 Z 83$ \\
\hline Ligand & B4P & Ap5A \\
\hline Carbon-hydrogen bonds & Gly40 : HA2-O1A & $\begin{array}{l}\text { Gly } 40: \mathrm{HA} 2-\mathrm{O} 2 \mathrm{~A} \\
\text { Arg 128: HD2-O4J }\end{array}$ \\
\hline (Electrostatic) Pi-cation & $\begin{array}{l}\operatorname{Arg} 128: \text { NH1 } \\
\operatorname{Arg} 128: \text { NH2 }\end{array}$ & $\begin{array}{l}\operatorname{Arg} 128: \text { NH1 } \\
\operatorname{Arg} 128: \text { NH2 }\end{array}$ \\
\hline (Hydrophobic) Pi-alkyl & $\operatorname{Arg} 128$ & $\operatorname{Arg} 128$ \\
\hline van der Waals & Asp140 & $\begin{array}{l}\text { Gly64 } \\
\text { Asp140 }\end{array}$ \\
\hline
\end{tabular}
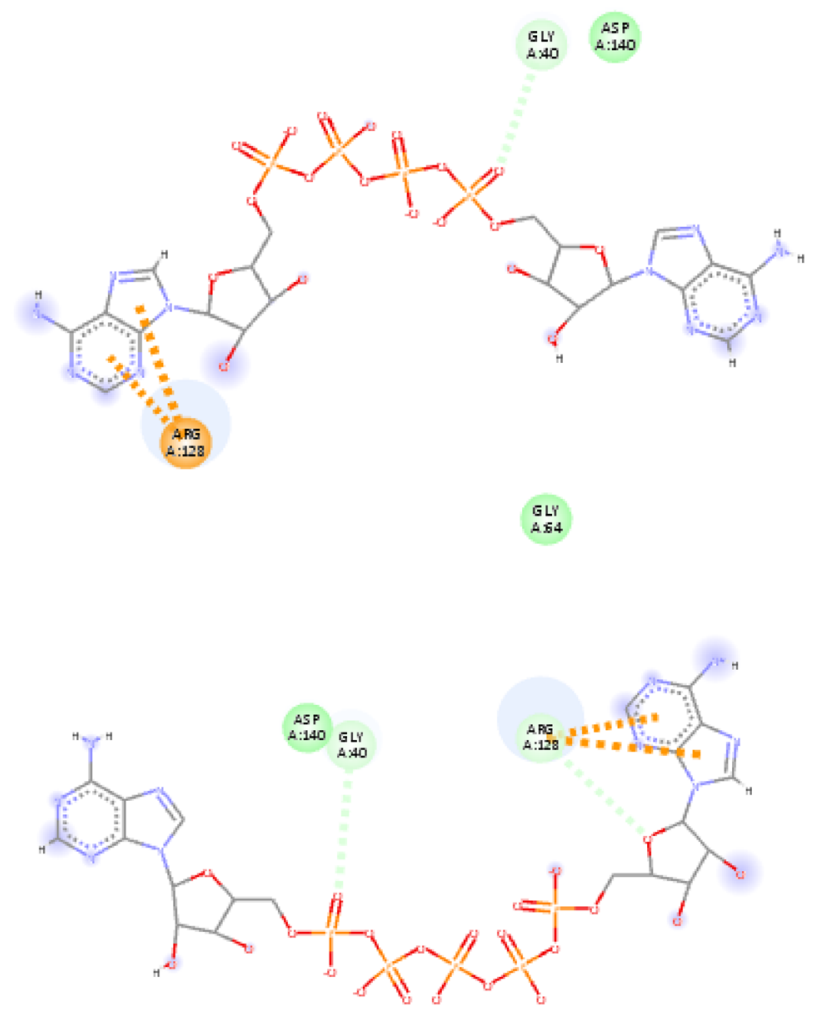

$\underset{\substack{G L Y \\ A .54}}{\sin }$

(b)

color for interactions: in light green are shown-carbon hydrogen bonds, orange-Pi-cation interactions, pink-alkyl/Pi-alkyl, greenvan der Waals. (Color figure online)

myastenic syndrome have been reported so far, in a recent study the authors have used the single-nucleotide polymorphism genotype array to homozygosity mapping for the disease-causing gene of one patient [77]. After filtering the variants which alter the protein function, the authors were able to identify the NM_001145128.2(AK9):c.332-14A > G variant of the $A K 9$ gene at a carrier of the disease with the chromosome 6 inherited form the mother. More, defective $\mathrm{N}$-glycosylation due to mutated $A K 9$ gene, could be compensated by uridine dietary supplements [78].

It was previously mentioned that the homozygous transversion c. $2018 \mathrm{~T}>\mathrm{G}$ leads to a missense mutation Leu673Pro in AK7 leads to primary male infertility due to the absence of the AK7 in sperm cells although the AK7 is present in airways epithelial cells, the mutation being in the the adenylate kinase domain but toward C-terminal near a dimerisation motif Dpy-30 [54]. In the Fig. 5 are presented 
Diabetic eyes

Parkinson (stages 5-6)

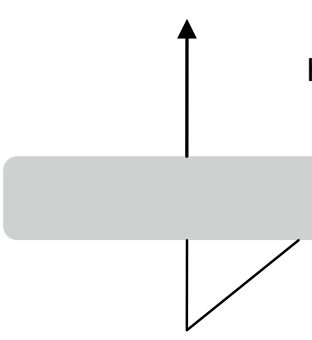

个AK1

Helmintic infections

Parkinson (stages 3-6)

Limbic encephalitis

\section{$\boldsymbol{\gamma} \mathbf{4}$}
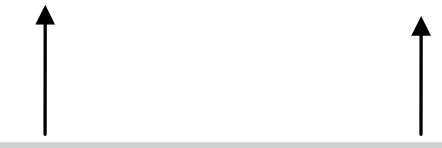

Inflammation / neurodegenerative disease
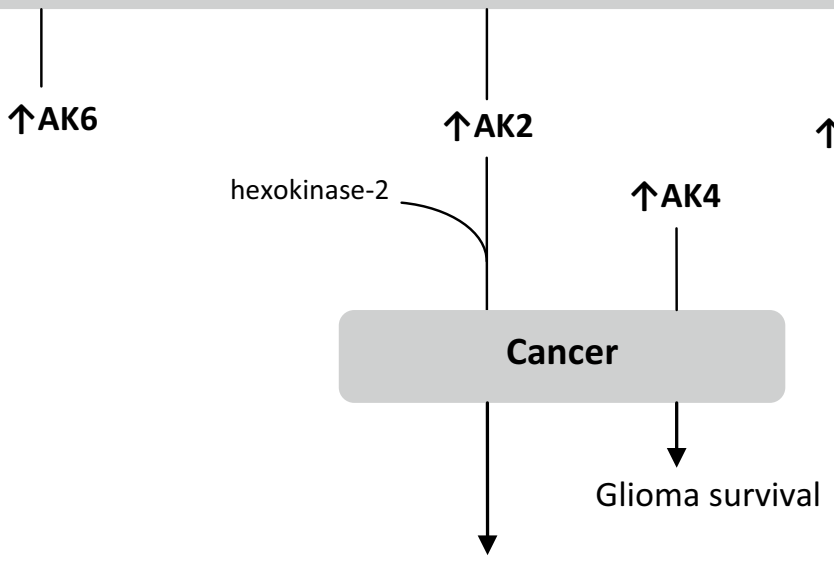

Neuroblastoma

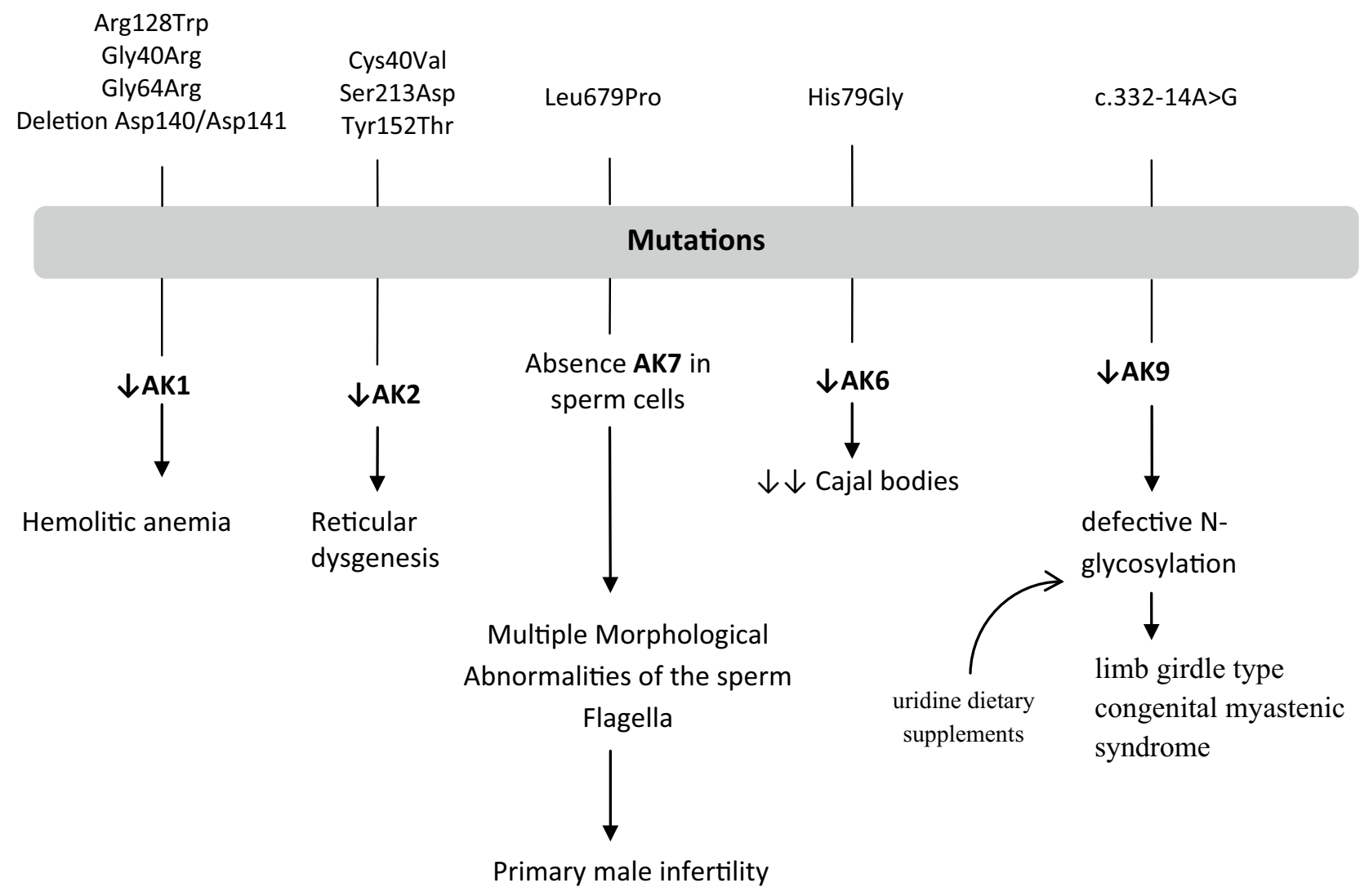

Fig. 5 The connections of human AKs and their mutations to human diseases 
the connections of human AKs isoenzymes, their mutations, to human diseases.

\subsection{Adenylate Kinases and Diagnosis Assay}

The presence of AKs - autoantibodies does not always suggest a pathogenetic role, but proved to be a valuable marker in early recognition of certain disorders. These kinds of assays are important mostly in rapidly progressive diseases, like autoimmune limbic encephalitis, when early treatment strategies could impede severe damages of vital body organs. The challenge is to establish clear criteria for determining the patients to whom AK-autoantibody screening is useful. As it was demonstrated limbic encephalitis it is not a paraneoplastic syndrome, but is related with underlying immune disorder [48-50]. AK5 auto-antibodies could be a valuable assay for this destructive disease.

In many clinical disorders it is difficult to identify and to measure a specific parameter effective to reveal specific pathological changes. Because the nucleotide metabolism is altered in many diseases, the energy metabolism plasticity of malignant cells could be helpful for developing new tools for accurate diagnosis in oncology. An interesting approach about usefulness of evaluation of metabolic phenotypes in human oral cancers was recently published. The metabolomic analysis of the oral cancer cell, after the knockdown of AK2 and phosphorylate glycerol kinase 1, enables the measure the level of different metabolites following the inhibition of metabolic enzymes [79]. The murine model tests demonstrated that $\mathrm{AK}$ is a useful biomarker for immunodiagnostic and vaccine development against tuberculosis [80].

Detection of the ATP along with AMP and ADP is sanitation monitoring system, applicable to stainless steel exposed to raw meat, intelligent alternative to conventional methods involving cultivation, species identification and counting colonies [81].

\subsection{Adenylate Kinases as Drugs Target}

The eukaryotic AMP-activated protein kinases (AMPK), as important regulator of energy homeostasis, proved to be potential therapeutical target for type-2 diabete, cancer or other metabolic diseases [82, 83].

Also, nucleoside monophosphate kinases have been investigated as potential targets for drug development. Structural and kinetics studies of wild type or mutated nucleoside monophosphate kinases show that non-nucleoside/nucleotide inhibitors should be investigated [84]. In a recent study, new thiazolidine derivatives have been shown to specifically inhibit bacterial AKs [85]. The differences between bacterial and human AKs could be exploited in designing new compounds suitable for the treatment of infection with multidrug resistant strains.
Further, do not forget HIV infection and drug resistance which remains one of the most demanding problems of HIV/ SIDA treatment. Essential host factors, like AK, are valid options to develop new drugs. To confirm this, genome-wide RNA-mediated interference (RNAi) screens proved to be a powerful instrument to demonstrate the link between the knockdown of certain regulatory protein and phenotypic changes [86]. RNAi turned out to successfully demonstrate an intrinsic connection of HIV-1 phenotypic changes and host regulatory protein kinase. So, human AK 1, along with other protein kinase-PRKACB-is in positive control of HIV-1 activity [87]. Notice, that adenyte kinase work in concert with other regulatory proteins, therefore experimental systems which permit high throughput screening may answer questions of medical importance.

\section{Conclusions}

Cellular energetic homeostasis depends on many regulatory proteins, AKs having an essential role. By focusing on the AK topic, I was trying to show how enzymes involved in energetic metabolism could be a solution for deciphering serious human diseases. Sometimes tissue distribution of the nine human adenylate kinases may suggest clinical manifestation for instance the association between AK5 and limbic encephalitis. More interesting are the isoenzymes AK1 and AK2 whose up or down regulations provide new perspective on immune modulation, metabolic syndrome or neurodegenerative diseases, but the molecular interplay between different AKs and other enzymes are not fully understood.

Some malignant cells are not exclusively glycolitic, but can produce ATP by mitochondrial oxidative phosphorylation; even it is not established the way of reorganization of respiratory chain. While AK2 is expressed in mitochondrial intermembrane space, its intracellular level is a valid marker to follow in metabolic dysregulation of malignant cells, heart hypertrophy or keloid disease.

AKs and AK-autoantibodies could be considered as relevant markers for severe diseases, like rapidly progressive dementia, when early immunotherapy is critical. AK 5 being specifically expressed in brain, AK5-autoantibodies should be considered in limbic encephalitis prior to irreversible damages. Also, AKs bring new hope for the diagnosis and prevention of infectious diseases, such as tuberculosis, where the lack of an effective vaccine is a pressing issue.

Taken together, the present review brings fresh insights in the open-ended field of AKs. The most demanding aspect of AK research is medical application either for clearing up molecular mechanisms underlying some clinical conditions, or for finding new positive links between $A K$ genes impairment and functional changes associated with rather severe, difficult to treat human diseases. Since ATP is the 
"exchange currency" most commonly used for cell energetic exchanges, AK2, which is located in the mitochondrial intermembrane space, is directly influenced by the alteration of cellular energy metabolism. Of the nine human AKs, eight isoenzymes-AK1, AK2, AK3, AK4, AK5, AK6, AK7, and AK9-have been in depth studied about their connection with pathological conditions. Further studies on AK and its mutants will bring new data to establish clear benchmarks to allow the comparison with other parameters in certain diseases.

Acknowledgements This work is dedicated to the memory of Professor Dr. Octavian Bârzu, my mentor in the study of nucleoside monophosphate kinases. This work was supported by a grant of Ministery of Research and Innovation, CNCS - UEFISCDI, project number PN-IIIP4-ID-PCCF-2016-0016, within PNCDI III. The author would like to thank the referees for their generous and useful comments that have greatly improved the manuscript.

\section{Compliance with Ethical Standards}

Conflict of interest The authors declare that she has no conflicts of interest.

\section{References}

1. Lanning NJ, Looyenga BD, Kauffman AL, Niemi NM, Sudderth J, DeBerardinis RJ, MacKeigan JP (2014) A mitochondrial RNAi screen defines cellular bioenergetic determinants and identifies an adenylate kinase as a key regulator of ATP levels. Cell Rep 7:907-917. https://doi.org/10.1016/j.celrep.2014.03.065

2. Berry MB, Meador B, Bilderback T, Liang P, Glaser M, Phillips GN (1994) The closed conformation of a highly flexible protein: the structure of $E$. coli adenylate kinase with bound AMP and AMPPNP. Proteins Struct Funct Bioinform 19:183-198. https:// doi.org/10.1002/prot.340190304

3. Rogne P, Rosselin M, Grundström C, Hedberg C, Sauer UH, Wolf-Watz M (2018) Molecular mechanism of ATP versus GTP selectivity of adenylate kinase. Proc Natl Acad Sci USA. https:// doi.org/10.1073/pnas.1721508115

4. Kuby SA, Hamada M, Johnson MS, Russell GA, Manship M, Palmieri RH, Fleming G, Bredt DS, Mildvan AS (1989) Studies on adenosine triphosphate transphosphorylases. XVIII. Synthesis and preparation of peptides and peptide fragments of rabbit muscle ATP-AMP transphosphorylase (adenylate kinase) and their nucleotide-binding properties. J Protein Chem 8:549-562. https ://doi.org/10.1007/BF01026438

5. Rundqvist L, Aden J, Sparrman T, Wallgren M, Olsson U, Wolf-Watz M (2009) Noncooperative folding of subdomains in adenylate kinase. Biochemistry 48:1911-1927. https://doi. org/10.1021/bi8018042

6. Wang Y, Makowski L (2018) Fine structure of conformational ensembles in adenylate kinase. Proteins 86:332-343. https://doi. org/10.1002/prot.25443

7. Noma $T$ (2005) Dynamics of nucleotide metabolism as a supporter of life phenomena. J Med Invest 52:127-136. https://doi. org/10.2152/jmi.52.127

8. Dzeja P, Terzic A (2009) Adenylate kinase and AMP signaling networks: metabolic monitoring, signal communication and body energy sensing. Int J Mol Sci 10:1729-1772. https://doi. org/10.3390/ijms10041729

9. Fujisawa K, Terai S, Takami T, Yamamoto N, Yamasaki T, Matsumoto T, Yamaguchi K, Owada Y, Nishina H, Noma T, Sakaida I (2016) Modulation of anti-cancer drug sensitivity through the regulation of mitochondrial activity by adenylate kinase 4. J Exp Clin Cancer Res 35:48. https://doi.org/10.1186/s13046-016-0322-2

10. Formoso E, Limongelli V, Parrinello M (2015) Energetics and structural characterization of the large-scale functional motion of adenylate kinase. Sci Rep 5:8425

11. Lin CY, Huang JY, Lo L-W (2013) Deciphering the catalysis-associated conformational changes of human adenylate kinase 1 with single-molecule spectroscopy. J Phys Chem B 117:13947-13955. https://doi.org/10.1021/jp4019537

12. Müller CW, Schlauderer GJ, Reinstein J, Schulz GE (1996) Adenylate kinase motions during catalysis: an energetic counterweight balancing substrate binding. Structure 4:147-156. https://doi. org/10.1016/S0969-2126(96)00018-4

13. Muller CW, Schulz GE (1988) Structure of the complex of adenylate kinase from Escherichia coli with the inhibitor P1,P5di(adenosine-5'-)pentaphosphate. J Mol Biol 202:909-912

14. Muller CW, Schulz GE (1992) Structure of the complex between adenylate kinase from Escherichia coli and the inhibitor Ap5A refined at 1.9 A resolution. A model for a catalytic transition state. J Mol Biol 224:159-177

15. Fukami-Kobayashi K, Nosaka M, Nakazawa A, Go M (1996) Ancient divergence of long and short isoforms of adenylate kinase: molecular evolution of the nucleoside monophosphate kinase family. FEBS Lett 385:214-220. https://doi.org/10.1016/00145793(96)00367-5

16. Wujak M, Czarnecka J, Gorczycka M, Hetmann A (2015) Human adenylate kinases-classification, structure, physiological and pathological importance. Postepy Hig Med Dosw (Online) 69:933-945. https://doi.org/10.5604/17322693.1165196

17. Dzeja PP, Zeleznikar RJ, Goldberg ND (1998) Adenylate kinase: kinetic behavior in intact cells indicates it is integral to multiple cellular processes. Mol Cell Biochem 184:169-182

18. Rice P, Longden I, Bleasby A (2000) EMBOSS: the European Molecular Biology Open Software Suite. Trends Genet 16:276-277

19. Ravera S, Calzia D, Panfoli I, Pepe IM, Morelli A (2007) Simultaneous detection of molecular weight and activity of adenylate kinases after electrophoretic separation. Electrophoresis 28:291300. https://doi.org/10.1002/elps.200600353

20. Haft DH, Loftus BJ, Richardson DL, Yang F, Eisen JA, Paulsen IT, White O (2001) TIGRFAMs: a protein family resource for the functional identification of proteins. Nucleic Acids Res 29:41-43

21. Panayiotou C, Solaroli N, Karlsson A (2014) The many isoforms of human adenylate kinases. Int J Biochem Cell Biol 49:75-83. https://doi.org/10.1016/j.biocel.2014.01.014

22. Panayiotou C, Solaroli N, Xu Y, Johansson M, Karlsson A (2011) The characterization of human adenylate kinases 7 and 8 demonstrates differences in kinetic parameters and structural organization among the family of adenylate kinase isoenzymes. Biochem J 433:527-534. https://doi.org/10.1042/BJ20101443

23. Lonergan KM, Chari R, DeLeeuw RJ, Shadeo A, Chi B, Tsao MS, Jones S, Marra M, Ling V, Ng R, MacAulay C, Lam S, Lam WL (2006) Identification of novel lung genes in bronchial epithelium by serial analysis of gene expression. Am J Respir Cell Mol Biol 35:651-661. https://doi.org/10.1165/rcmb.2006-0056OC

24. Lee Y, Kim JW, Lee IA, Kang HB, Choe YK, Lee HG, Lim JS, Kim HJ, Park C, Choe IS (1996) Cloning and characterization of cDNA for human adenylate kinase 2A. Biochem Mol Biol Int 39:833-842

25. Lee Y, Kim JW, Lee SM, Kim HJ, Lee KS, Park C, Choe IS (1998) Cloning and expression of human adenylate kinase 2 isozymes: 
differential expression of adenylate kinase 1 and 2 in human muscle tissues. J Biochem 123:47-54

26. Sorrentino V, Menzies KJ, Auwerx J (2018) Repairing mitochondrial dysfunction in disease. Annu Rev Pharmacol Toxicol. https ://doi.org/10.1146/annurev-pharmtox-010716-104908

27. Liu R, Xu H, Wei Z, Wang Y, Lin Y, Gong W (2008) Crystal structure of human adenylate kinase 4 (L171P) suggests the role of hinge region in protein domain motion. Biochem Biophys Res Commun 379:92-97. https://doi.org/10.1016/j.bbrc.2008.12.012

28. Ren H, Wang L, Bennett M, Liang Y, Zheng X, Lu F, Li L, Nan J, Luo M, Eriksson S, Zhang C, Su X-D (2005) The crystal structure of human adenylate kinase 6: an adenylate kinase localized to the cell nucleus. Proc Natl Acad Sci USA 102:303-308. https://doi. org/10.1073/pnas.0407459102

29. Drakou CE, Malekkou A, Hayes JM, Lederer CW, Leonidas DD, Oikonomakos NG, Lamond AI, Santama N, Zographos SE (2012) hCINAP is an atypical mammalian nuclear adenylate kinase with an ATPase motif: structural and functional studies. Proteins 80:206-220. https://doi.org/10.1002/prot.23186

30. Amiri M, Conserva F, Panayiotou C, Karlsson A, Solaroli N (2013) The human adenylate kinase 9 is a nucleoside mono- and diphosphate kinase. Int J Biochem Cell Biol 45:925-931. https:// doi.org/10.1016/j.biocel.2013.02.004

31. (2018) Focusing on mitochondrial form and function. Nat Cell Biol. https://doi.org/10.1038/s41556-018-0139-7, https://www. nature.com/articles/s41556-018-0139-7.pdf

32. Gloria-Bottini F, Neri A, Pietropolli A, Bottini E, Magrini A (2013) Ak 1 genetic polymorphism and season of conception. Eur J Obstet Gynecol Home. https://doi.org/10.1016/j.ejogr b.2012.09.019

33. Hewitson JP, Grainger JR, Maizels RM (2009) Helminth immunoregulation: the role of parasite secreted proteins in modulating host immunity. Mol Biochem Parasitol 167:1-11. https://doi. org/10.1016/J.MOLBIOPARA.2009.04.008

34. McSorley HJ, Hewitson JP, Maizels RM (2013) Immunomodulation by helminth parasites: defining mechanisms and mediators. Int J Parasitol 43:301-310. https://doi.org/10.1016/j.ijpar a.2012.11.011

35. Gao Y, Zhou X, Wang H, Liu R, Ye Q, Zhao Q, Ming Z, Dong $\mathrm{H}$ (2017) Immunization with recombinant schistosome adenylate kinase 1 partially protects mice against Schistosoma japonicum infection. Parasitol Res 116:1665-1674. https://doi.org/10.1007/ s00436-017-5441-y

36. Cao Z, Huang Y, Wang T (2017) Schistosomiasis japonica control in domestic animals: progress and experiences in China. Front Microbiol 8:2464. https://doi.org/10.3389/fmicb.2017.02464

37. Loukovaara S, Sandholm J, Aalto K, Liukkonen J, Jalkanen S, Yegutkin GG (2017) Deregulation of ocular nucleotide homeostasis in patients with diabetic retinopathy. J Mol Med 95:193-204. https://doi.org/10.1007/s00109-016-1472-6

38. Notomi S, Hisatomi T, Murakami Y, Terasaki H, Sonoda S, Asato R, Takeda A, Ikeda Y, Enaida H, Sakamoto T, Ishibashi T (2013) Dynamic increase in extracellular ATP accelerates photoreceptor cell apoptosis via ligation of P2RX7 in subretinal hemorrhage. PLoS ONE. https://doi.org/10.1371/journal.pone.0053338

39. Zhong Y, Yang Z, Huang WC, Luo X (2013) Adenosine, adenosine receptors and glaucoma: an updated overview. Biochim Biophys Acta 1830:2882-2890. https://doi.org/10.1016/j.bbage n.2013.01.005

40. Sanderson J, Dartt DA, Trinkaus-Randall V, Pintor J, Civan MM, Delamere NA, Fletcher EL, Salt TE, Grosche A, Mitchell CH (2014) Purines in the eye: recent evidence for the physiological and pathological role of purines in the RPE, retinal neurons, astrocytes, Müller cells, lens, trabecular meshwork, cornea and lacrimal gland. Exp Eye Res 127:270-279. https:// doi.org/10.1016/j.exer.2014.08.009

41. Ito K, Suda T (2014) Metabolic requirements for the maintenance of self-renewing stem cells. Nat Rev Mol Cell Biol 15:243-256. https://doi.org/10.1038/nrm3772

42. Burkart A, Shi X, Chouinard M, Corvera S (2011) Adenylate kinase 2 links mitochondrial energy metabolism to the induction of the unfolded protein response. J Biol Chem 286:4081-4089. https://doi.org/10.1074/jbc.M110.134106

43. Pannicke U, Hönig M, Hess I, Friesen C, Holzmann K, Rump EM, Barth TF, Rojewski MT, Schulz A, Boehm T, Friedrich W, Schwarz K (2009) Reticular dysgenesis (aleukocytosis) is caused by mutations in the gene encoding mitochondrial adenylate kinase 2. Nat Genet 41:101-105. https://doi.org/10.1038/ng.265

44. Klein C (2009) Congenital neutropenia. Hematology 2009:344350. https://doi.org/10.1182/asheducation-2009.1.344

45. Six E, Lagresle-Peyrou C, Susini S, De Chappedelaine C, Sigrist N, Sadek H, Chouteau M, Cagnard N, Fontenay M, Hermine O, Chomienne C, Reynier P, Fischer A, André-Schmutz I, Gueguen $\mathrm{N}$, Cavazzana M (2015) AK2 deficiency compromises the mitochondrial energy metabolism required for differentiation of human neutrophil and lymphoid lineages. Cell Death Dis 6:e1856. https ://doi.org/10.1038/cddis.2015.211

46. Chandel NS (2014) Mitochondria as signaling organelles. BMC Biol 12:34. https://doi.org/10.1186/1741-7007-12-34

47. Meyer A, Laverny G, Bernardi L, Charles AL, Alsaleh G, Pottecher J, Sibilia J, Geny B (2018) Mitochondria: an organelle of bacterial origin controlling inflammation. Front Immunol 9:1-8. https://doi.org/10.3389/fimmu.2018.00536

48. Tüzün E, Rossi JE, Karner SF, Centurion AF, Dalmau J (2007) Adenylate kinase 5 autoimmunity in treatment refractory limbic encephalitis. J Neuroimmunol 186:177-180. https://doi. org/10.1016/j.jneuroim.2007.03.015

49. Do L-D, Chanson E, Desestret V, Joubert B, Ducray F, Brugière S, Couté Y, Formaglio M, Rogemond V, Thomas-Antérion C, Borrega L, Laurens B, Tison F, Curot J, De Brouker T, Lebrun-Frenay C, Delattre J-Y, Antoine J-C, Honnorat J (2017) Characteristics in limbic encephalitis with anti-adenylate kinase 5 autoantibodies. Neurology 88:514-524. https://doi.org/10.1212/WNL.00000 00000003586

50. Ng ASL, Kramer J, Centurion A, Dalmau J, Huang E, Cotter JA, Geschwind MD (2015) Clinico-pathological correlation in adenylate kinase 5 autoimmune limbic encephalitis. J Neuroimmunol 287:31-35. https://doi.org/10.1016/j.jneuroim.2015.08.009

51. Zhai R, Meng G, Zhao Y, Liu B, Zhang G, Zheng X (2006) A novel nuclear-localized protein with special adenylate kinase properties from Caenorhabditis elegans. https://doi.org/10.1016/j. febslet.2006.05.074

52. Feng X, Yang R, Zheng X, Zhang F (2012) Identification of a novel nuclear-localized adenylate kinase 6 from Arabidopsis thaliana as an essential stem growth factor. Plant Physiol Biochem 61:180-186. https://doi.org/10.1016/j.plaphy.2012.10.002

53. Van Horssen R, Janssen E, Peters W, Van de Pasch L, Te Lindert MM, Van Dommelen MMT, Linssen PC, Ten Hagen TLM, Fransen JAM, Wieringa B (2009) Modulation of cell motility by spatial repositioning of enzymatic ATP/ADP exchange capacity. J Biol Chem 284:1620-1627. https://doi.org/10.1074/jbc.M8069 74200

54. Lorès $\mathrm{P}$, Coutton $\mathrm{C}, \mathrm{El}$ Khouri E, Stouvenel L, Givelet M, Thomas L, Rode B, Schmitt A, Louis B, Sakheli Z, Chaudhry M, Fernandez-Gonzales A, Mitsialis A, Dacheux D, Wolf JP, Papon JF, Gacon G, Escudier E, Arnoult C, Bonhivers M, Savinov SN, Amselem S, Ray PF, Dulioust E, Touré A (2018) Homozygous missense mutation L673P in adenylate kinase 7 (AK7) leads to primary male infertility and multiple morphological anomalies of 
the flagella but not to primary ciliary dyskinesia. Hum Mol Genet 27:1196-1211. https://doi.org/10.1093/hmg/ddy034

55. Afzelius BA, Eliasson R (1979) Flagellar mutants in man: on the heterogeneity of the immotile-cilia syndrome. J Ultrastruct Res 69:43-52

56. Afzelius BA (1976) A human syndrome caused by immotile cilia. Science 193:317-319

57. Lucas JS, Barbato A, Collins SA, Goutaki M, Behan L, Caudri D, Dell S, Eber E, Escudier E, Hirst RA, Hogg C, Jorissen M, Latzin P, Legendre M, Leigh MW, Midulla F, Nielsen KG, Omran H, Papon JF, Pohunek P, Redfern B, Rigau D, Rindlisbacher B, Santamaria F, Shoemark A, Snijders D, Tonia T, Titieni A, Walker WT, Werner C, Bush A, Kuehni CE (2017) European Respiratory Society guidelines for the diagnosis of primary ciliary dyskinesia. Eur Respir J. https://doi.org/10.1183/13993003.01090-2016

58. Fernandez-Gonzalez A, Kourembanas S, Wyatt TA, Mitsialis SA (2009) Mutation of murine adenylate kinase 7 underlies a primary ciliary dyskinesia phenotype. Am J Respir Cell Mol Biol 40:305-313. https://doi.org/10.1165/rcmb.2008-0102OC

59. Seccia TM, Atlante A, Vulpis V, Marra E, Passarella S, Pirrelli A (1998) Mitochondrial energy metabolism in the left ventricular tissue of spontaneously hypertensive rats: abnormalities in both adeninenucleotide and phosphate translocators and enzyme adenylate-kinase and creatine-phosphokinase activities. Clin Exp Hypertens 20:345-358

60. Wang ZH, Cai XL, Wu L, Yu Z, Liu JL, Zhou ZN, Liu J, Yang HT (2012) Mitochondrial energy metabolism plays a critical role in the cardioprotection afforded by intermittent hypobaric hypoxia. Exp Physiol 97:1105-1118. https://doi.org/10.1113/expphysiol .2012 .065102

61. Ge Y, Molloy MP, Chamberlain JS, Andrews PC (2003) Proteomic analysis of mdx skeletal muscle: great reduction of adenylate kinase 1 expression and enzymatic activity. Proteomics 3:1895-1903. https://doi.org/10.1002/pmic.200300561

62. Myers RW, Guan H-P, Ehrhart J, Petrov A, Prahalada S, Tozzo E, Yang X, Kurtz MM, Trujillo M, Gonzalez Trotter D, Feng D, Xu S, Eiermann G, Holahan MA, Rubins D, Conarello S, Niu X, Souza SC, Miller C, Liu J, Lu K, Feng W, Li Y, Painter RE, Milligan JA, He H, Liu F, Ogawa A, Wisniewski D, Rohm RJ, Wang L, Bunzel M, Qian Y, Zhu W, Wang H, Bennet B, LaFranco Scheuch L, Fernandez GE, Li C, Klimas M, Zhou G, van Heek M, Biftu T, Weber A, Kelley DE, Thornberry N, Erion MD, Kemp DM, Sebhat IK (2017) Systemic pan-AMPK activator MK-8722 improves glucose homeostasis but induces cardiac hypertrophy. Science 357:507-511. https://doi.org/10.1126/science.aah5582

63. Kodiha M, Stochaj U (2011) AMP kinase: the missing link between type 2 diabetes and neurodegenerative diseases? Trends Mol Med 17:613-614. https://doi.org/10.1016/j.molme d.2011.07.001

64. Kang S, Lee YH, Lee JE (2017) Metabolism-centric overview of the pathogenesis of Alzheimer's Disease. Yonsei Med J 58:479488. https://doi.org/10.3349/ymj.2017.58.3.479

65. Baldassarre MPA, Andersen A, Consoli A, Knop FK, Vilsbøll T (2018) Cardiovascular biomarkers in clinical studies of type 2 diabetes. Diabetes Obes Metab. https://doi.org/10.1111/dom.13247

66. Miller E, Morel A, Saso L, Saluk J (2014) Isoprostanes and neuroprostanes as biomarkers of oxidative stress in neurodegenerative diseases. Oxid Med Cell Longev. https://doi. org/10.1155/2014/572491

67. Garcia-Esparcia P, Hernández-Ortega K, Ansoleaga B, Carmona M, Ferrer I (2015) Purine metabolism gene deregulation in Parkinson's disease. Neuropathol Appl Neurobiol 41:926-940. https ://doi.org/10.1111/nan.12221

68. WARBURG O (1956) On respiratory impairment in cancer cells. Science 124:269-270
69. de Padua MC, Delodi G, Vučetić M, Durivault J, Vial V, Bayer P, Rodrigues Noleto G, Mazure NM, Ždralević M, Pouysségur J (2017) Disrupting glucose-6-phosphate isomerase fully suppresses the "Warburg effect" and activates OXPHOS with minimal impact on tumor growth except in hypoxia. Oncotarget 8:87623-87637. https://doi.org/10.18632/oncotarget.21007

70. Ounpuu L, Klepinin A, Pook M, Teino I, Peet N, Paju K, Tepp K, Chekulayev V, Shevchuk I, Koks S, Maimets T, Kaambre T (2017) 2102Ep embryonal carcinoma cells have compromised respiration and shifted bioenergetic profile distinct from H9 human embryonic stem cells. Biochim Biophys Acta 1861:2146-2154. https:// doi.org/10.1016/j.bbagen.2017.05.020

71. Klepinin A, Chekulayev V, Timohhina N, Shevchuk I, Tepp K, Kaldma A, Koit A, Saks V, Kaambre T (2014) Comparative analysis of some aspects of mitochondrial metabolism in differentiated and undifferentiated neuroblastoma cells. J Bioenerg Biomembr 46:17-31. https://doi.org/10.1007/s10863-013-9529-5

72. Liu R, Ström A-L, Zhai J, Gal J, Bao S, Gong W, Zhu H, Strom A-L, Zhai J, Gal J, Bao S, Gong W, Zhu H (2009) Enzymatically inactive adenylate kinase 4 interacts with mitochondrial ADP/ ATP translocase. Int J Biochem Cell Biol 41:1371-1380. https:// doi.org/10.1016/j.biocel.2008.12.002

73. Matsuura S, Igarashi M, Tanizawa Y, Yamada M, Kishi F, Kajii T, Fujii H, Miwa S, Sakurai M, Nakazawa A (1989) Human adenylate kinase deficiency associated with hemolytic anemia. A single base substitution affecting solubility and catalytic activity of the cytosolic adenylate kinase. J Biol Chem 264:10148-10155

74. Corrons J-LV, Garcia E, Tusell JJ, Varughese KI, West C, Beutler E (2003) Red cell adenylate kinase deficiency: molecular study of 3 new mutations (118G $>$ A, 190G $>$ A, and GAC deletion) associated with hereditary nonspherocytic hemolytic anemia. Blood 102:353-356. https://doi.org/10.1182/blood-2002-07-2288

75. Shin Y, Brangwynne CP (2017) Liquid phase condensation in cell physiology and disease. Science 357:eaaf4382. https://doi. org/10.1126/science.aaf4382

76. Lam C-W, Wong K-S, Leung H-W, Law C-Y (2017) Limb girdle myasthenia with digenic RAPSN and a novel disease gene AK9 mutations. Eur J Hum Genet 25:192-199. https://doi.org/10.1038/ ejhg.2016.162

77. Rodriguez Cruz PM, Palace J, Beeson D (2014) Congenital myasthenic syndromes and the neuromuscular junction. Curr Opin Neurol 27:566-575. https://doi.org/10.1097/WCO.0000000000 000134

78. Urasaki Y, Pizzorno G, Le TT (2014) Uridine affects liver protein glycosylation, insulin signaling, and heme biosynthesis. PLoS ONE 9:e99728. https://doi.org/10.1371/journal.pone.0099728

79. Hye Ji E, Cui L, Yuan X, Cheng S, Messadi D, Yan X, Hu S, Yan X (2017) Metabolomic analysis of human oral cancer cells with adenylate kinase 2 or phosphorylate glycerol kinase 1 inhibition. J Cancer. https://doi.org/10.7150/jca.17521

80. Xiao Y, Sha W, Tian Z, Chen Y, Ji P, Sun Q, Wang H, Wang S, Fang Y, Wen H-L, Zhao H, Lu J, Xiao H, Fan X, Shen H, Wang Y (2016) Adenylate kinase: a novel antigen for immunodiagnosis and subunit vaccine against tuberculosis. J Mol Med 94:823-834. https://doi.org/10.1007/s00109-016-1392-5

81. Bakke M, Suzuki S (2018) Development of a novel hygiene monitoring system based on the detection of total adenylate (ATP + ADP + AMP). J Food Prot 81:729-737. https://doi. org/10.4315/0362-028X.JFP-17-432

82. Day EA, Ford RJ, Steinberg GR (2017) AMPK as a therapeutic target for treating metabolic diseases. Trends Endocrinol Metab 28:545-560. https://doi.org/10.1016/j.tem.2017.05.004

83. Carling D (2017) AMPK signalling in health and disease. Curr Opin Cell Biol 45:31-37. https://doi.org/10.1016/j. ceb.2017.01.005 
84. Egeblad-Welin L, Welin M, Wang L, Eriksson S (2007) Structural and functional investigations of Ureaplasma parvum UMP kinase-a potential antibacterial drug target. FEBS J 274:64036414. https://doi.org/10.1111/j.1742-4658.2007.06157.x

85. Ionescu MI, Oniga O (2018) Molecular docking evaluation of (E)-5-arylidene-2-thioxothiazolidin-4-one derivatives as selective bacterial adenylate kinase inhibitors. Molecules. https://doi. org/10.3390/molecules23051076

86. Sharma S, Rao A (2009) RNAi screening: tips and techniques. Nat Immunol 10:799-804. https://doi.org/10.1038/ni0809-799
87. Jiang W-M, Zhang X-Y, Zhang Y-Z, Liu L, Lu H-Z (2014) A high throughput RNAi screen reveals determinants of HIV-1 activity in host kinases. Int J Clin Exp Pathol 7:2229-2237

Publisher's Note Springer Nature remains neutral with regard to jurisdictional claims in published maps and institutional affiliations. 